Chem. Phys. Lipids 5 (1970) 178-192 @ North-Holland Publ. Co., Amsterdam.

\title{
THE GALACTOSYL MOIETY OF BRAIN CEREBROSIDES
}

\author{
NORMAN S. RADIN \\ Mental Health Research Institute, University of Michigan, \\ Ann Arbor, Michigan 48104, U.S.A.
}

Thirteen years ago I found that galactosyl ceramide undergoes metabolic conversion in the brain of young rats ${ }^{1}$ ). Month-old rats were injected with

${ }^{14} \mathrm{C}$-galactose, rats were sacrificed at various intervals, and the brain lipids were fractionated according to the following scheme (fig. 1).

The radioactivity in the galactose of each lipid group is shown in fig. 2, which plots total activity against time. The top curve, from cerebrosides, shows a slow but distinct conversion of brain cerebroside. Judging by the somewhat slower rate of rise in sulfatide activity (bottom curve), this conversion could - in part, at least - be due to conversion of cerebroside to sulfatide. Confirmation of this guess came from the work of Bachhawat and McKhann some years later ${ }^{2,3}$ ). (The middle curve, for gangliosides, shows this group of lipids has a higher turnover rate than cerebrosides.)

There was some reason to believe that another portion of the metabolic conversion of cerebrosides involved hydrolysis of the galactosidic linkage. Fujino $^{4}$ ) and Thannhauser and Reichel ${ }^{5}$ ) had reported rather incomplete evidence for the presence in brain of a cerebroside galactosidase, and it was also known that cerebrosides can disappear in demyelinative processes. Accordingly, we made some radioactive cerebroside and looked for the hydrolysis.

The preparation of the labeled lipid was based on a procedure of Carter and Fujino ${ }^{6}$ ) for the formation of psychosine sulfate (fig. 3). The first reaction is formulated in an unusual way in order to explain something we found a few years later: when a mixture of cerebrosides is used, containing both hydroxy and nonhydroxy fatty acids, one obtains a great deal of unhydrolyzed cerebroside of the latter type. Carter and Koob simultaneously made a similar observation. We have not made a serious study of the reaction, but it looks as though only the hydroxy fatty acid amide bond is attacked by the barium ions, and I suggest the effect involves formation of a barium chelate of hydroxy fatty acids, shown in the top equation.

The last step in the synthesis is an adaptation of the procedure of Shapiro 
and Flowers ${ }^{7}$ ), which worked very well for this application. Stearate-labeled cerebroside was made the same way and converted to ceramide by the procedure of Carter, Rothfus and Gigg ${ }^{8}$ ).

When the ${ }^{14} \mathrm{C}$-lipids were injected directly into the brains of young rats, the following results were obtained (table 1). Substantial amounts of cerebroside and ceramide fatty acids were found in esterified form (more in the case of the labeled stearate). This showed that the amide linkage of both sphingolipids underwent turnover. In addition, the lignocerate became converted to hydroxy acids (line 6) but negligible conversion to sulfatide

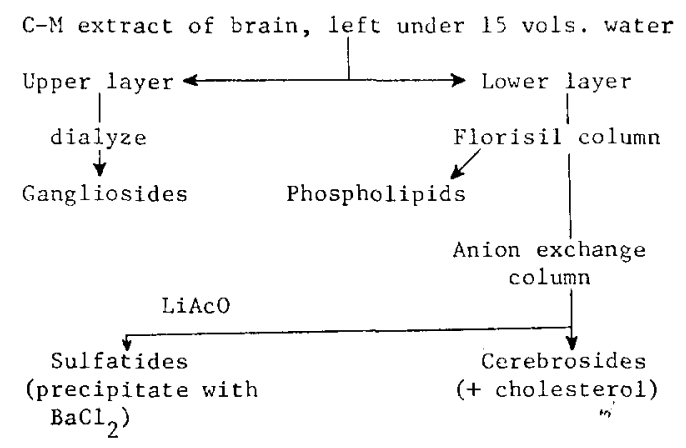

Fig. 1 Galactolipid fractionation ${ }^{1}$ ).

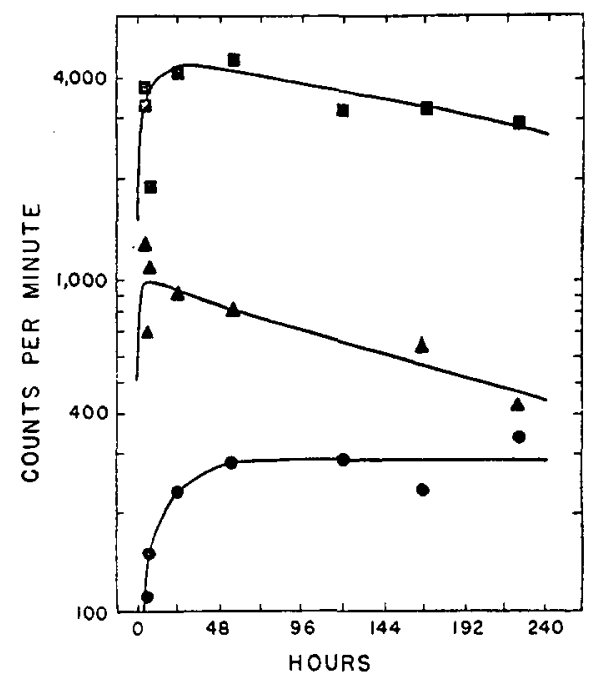

Fig. 2. ${ }^{14} \mathrm{C}$ content of total rat brain lipid-bound galactose as a function of number of hours after injection. Top curve, cerebrosides; middle curve, gangliosides; bottom curve, sulfatides. 
occurred. The main additional reactions seemed to be conversion of cerebroside to ceramide, and conversion of ceramide to sphingomyelin.

This seemed like direct evidence for the existence in brain of a cerebroside galactosidase, and we were encouraged to seek the enzyme in vitro. Because of the presence in brain of much endogenous membrane-bound cerebroside, which dilutes the radioactive cerebroside, we restricted our initial efforts to the cytosol, or highspeed supernatant fraction of brain. The enzyme was found by Amiya Hajra in this laboratory ${ }^{9}$ ). Its $p \mathrm{H}$ optimum is fairly low, like other glycosidases: 4.5. It requires a bile salt for activity, although deoxycholate and taurochenodeoxycholate are ineffective. In the

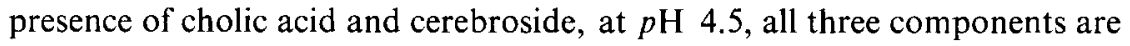
insoluble: enzyme, cholate, and cerebroside. It seems as though the cere-

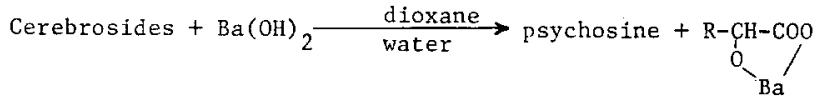

$$
\begin{aligned}
& \text { Silver lignocerate }+\mathrm{Br}_{2} \stackrel{\mathrm{CCl}_{4}}{\longrightarrow} \mathrm{C}_{23} \mathrm{H}_{47} \mathrm{Br} \\
& \text { Tricosanyl bromide }+\mathrm{K}^{14} \mathrm{CN} \stackrel{\mathrm{EtOH}}{\longrightarrow} \mathrm{C}_{23} \mathrm{H}_{47} \mathrm{CN} \frac{\mathrm{OH}^{-}}{\mathrm{H}^{+}} \longrightarrow \\
& { }^{14} \mathrm{C} \text {-1ignoceric acid thionyl chloride, 1ignoceroy } 1 \text { chloride } \\
& \text { Psychosine sulfate }+ \text { lignoceroyl chloride } \underset{\text { tetrahydrofuran }}{\longrightarrow} \\
& \text { acy1-1abeled cerebroside }
\end{aligned}
$$

Fig. 3. From Kopaczyk and Radin ${ }^{31}$ ).

TABLE 1

Recovered ${ }^{14} \mathrm{C}$ in lipid fractions two days after injection

$\begin{array}{cc}\text { Lignoceroyl } & \text { Stearoyl } \\ \text { psychosine } & \text { sphingosine }\end{array}$

Ester-linked fatty acids

Cholesterol

Ceramides

Sphingomyelins

Cerebrosides

Cerebroside hydroxy acids

Sulfatides

Ganglioside fatty acids

Total lipids minus gangliosides

\subsection{4}

0.32

0.45

1.63

1.07

0.09

38
8.67

0.05

0.13

Figures are percent of injected lipid, labeled in the lignocerate or stearate moiety. 
broside cannot be hydrolyzed unless it is bound in a membrane-like matrix.

Cholate is presumably a nonphysiological cofactor for a brain enzyme and we have not yet a good idea as to the natural cofactor, although fatty acids have some activating power.

We achieved some purification of the cytosol enzyme, but virtually every manipulation rendered it insoluble. David Bowen tried his hand at the purification, starting with the particulate fraction of brain, since a fractionation study indicated it was present in the lysosomes. To speed the assay procedure, we prepared cerebroside labeled in the galactose moiety, since separating liberated galactose from unhydrolyzed cerebroside can be done by solvent partition. The labeling method was worked out by William Suomi, a student of Bernard Agranoff. It took advantage of the ability of a fungal enzyme, galactose oxidase, to work in a $50 \%$ tetrahydrofuran medium, which also has the ability to dissolve a reasonable amount of cerebroside ${ }^{10}$ ). The enzyme oxidizes the 6-position of a variety of galactosides to an aldehyde, which can then be reduced to the original group with tritium-labeled sodium borohydride. Fortunately Lars Svennerholm told us of the availability of the oxidase from an excellent commercial source, AB Kabi, in Stockholm.

We succeeded in solubilizing the enzyme in micellar form with sodium cholate, but various further attempts at purification reaggregated the enzyme $^{11}$ ). Success came by digesting the cholate extract with a mixture of pancreatic enzymes; these left the cerebrosidase intact. After this we could use relatively conventional methods, although it was apparent that membrane-forming components were still present. Table 2 shows the summary of

TABLE 2

Purification of cerebrosidase from rat brain.

The data are taken from a large scale isolation starting with $250 \mathrm{~g}$ of brain, shipped on ice and utilized within $24 \mathrm{~h}$. Enzyme units are nmoles of stearoyl psychosine hydrolyzed per $\mathbf{h}$. Fraction I was assayed under conditions similar to fractions II and III, that is, after suspension in $6 \%$ cholate and dialysis for $36 \mathrm{~h}$ against buffer

\begin{tabular}{ccccc}
\hline Fraction & $\begin{array}{c}\text { Total protein } \\
\text { (mg/g brain) }\end{array}$ & $\begin{array}{c}\text { Specific } \\
\text { activity } \\
\text { (units/mg } \\
\text { protein) }\end{array}$ & $\begin{array}{c}\text { Purification } \\
\text { factor }\end{array}$ & $\begin{array}{c}\text { Recovery } \\
(\%)\end{array}$ \\
\hline I. Crude lysosomal particles & 35.4 & 0.58 & 1 & 100 \\
II. Cholate extract & 24.7 & 1.5 & 2.6 & 181 \\
III. Pancreatin-treated extract & 2.5 & 21 & 37 & 257 \\
IV. Sephadex effluent & 1.9 & 25 & 42 & 230 \\
V. Ultrafiltered concentrate & 0.95 & 40 & 68 & 183 \\
VI. Following electrophoresis & 0.30 & 67 & 115 & 98 \\
VII. Following DEAE-Sephadex & 0.037 & 159 & 275 & 29 \\
VIII. pH 5 supernatant & 0.030 & 182 & 314 & 27 \\
\hline
\end{tabular}


the purification procedure which, with rat brain particles, yielded over $300-$ fold purification. On a total brain basis, the purification was higher than this as our first step involved centrifugal isolation of an active particle fraction.

The enzyme could be somewhat separated from another galactosidase in brain, which acted on nitrophenyl- $\beta$-galactoside, as well as from arylsulfatase, which apparently converts sulfatide to cerebroside. Separation from ceramidase, assayed by the procedure of $\mathrm{Gatt}^{12}$ ), was rather poor. It is interesting that several sphingolipid-hydrolyzing enzymes seem to be so similar chromatographically, as well as resistant to pancreatic digestion.

The cerebrosidase proved to be unstable after the ion exchange step, possibly because some stabilizing acidic lipid was removed by the column. We found that sodium taurocholate stabilized it, but this is not readily removed; $50 \%$ glycerol proved to be excellent for storage at $-20^{\circ} \mathrm{C}$. This had to be dialyzed away before assay, as glycerol inhibits the enzyme's action $^{13}$ ).

Preliminary analysis showed that the enzyme is concentrated in the white matter, and that old rats have more enzyme than young rats. These observations make sense, since cerebrosides - presumably the natural substrate for the galactosidase - are more concentrated in white matter and old brains.

\section{TABLE 3}

Cerebroside galactosidase assay

Brain homogenate in Tris-Mg-mercaptoethanol:

Add Na-cholate + pancreatin; incubate overnight at $4^{\circ} \mathrm{C}$.

Discard $100000 \mathrm{~g}$ pellet.

Add Na-citrate $p \mathrm{H} \mathrm{3}$; discard 14000 spnt.

Suspend pellet in Tris-Mg-ME; use $1 \mathrm{mg}$ or less of brain equivalent.

Incubate with ${ }^{3} \mathrm{H}$-cerebroside (emulsified in Tween $20+$ Myrj $59+\mathrm{Na}$ taurocholate) + Tris oleate + citrate $p \mathrm{H} 4.5$.

After $3 \mathrm{hr}$ at $37^{\circ} \mathrm{C}$, isolate the galactose by Folch partitioning; dry down upper layer.

Dissolve residue in $0.5 \mathrm{ml}$ water + BioSolve BBS-3+ toluene + PPOP + POPOP.

On the basis of the above study, we developed an assay procedure for cerebrosidase that could be used with whole brain ${ }^{14}$ ) (table 3 ). The digestion and acid precipitation remove most of the endogenous cerebroside, so good linearity is obtained with respect to tissue weight. The oleate used in the hydrolytic step doubles the activity. The whole procedure is obviously very complex and only an optimistic, determined person can do it effectively.

Our first study with the new assay was a comparison in rats of different ages. This seemed of interest because of the peculiar place of cerebrosides in 
the developmental pattern of brain. Let me remind you of this with some of our data, taken from a study with Yasuo Kishimoto and Ewart Davies ${ }^{15}$ ). Fig. 4 shows the changes in total brain ganglioside (shown as ganglioside stearate, the major fatty acid in this lipid class). This material accumulates steadily during the first 3 weeks of life, then the rate of accretion suddenly drops to a small value for a month, after which there is an actual decrease in

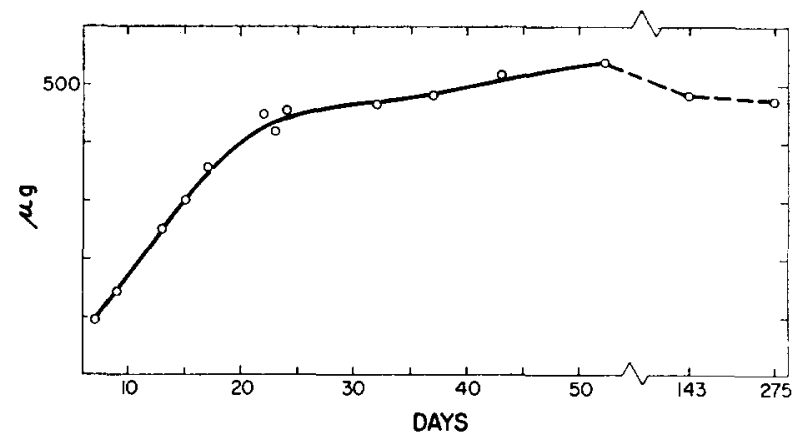

Fig. 4. Ganglioside stearate content of whole rat brain as a function of age.

weight. Fig. 5 shows a similar sequence of events for the 3 major ester-linked fatty acids, oleate, stearate, and palmitate. Palmitate deposition stops almost completely at 3 weeks and stearate deposition is almost completely stopped at 40 days. Oleate shows a more consistent rate of deposition for a few months. By way of contrast (fig. 6), cerebroside - pooled in this experiment with sulfatide - is barely deposited before 9 days of age. By 15 days of age,

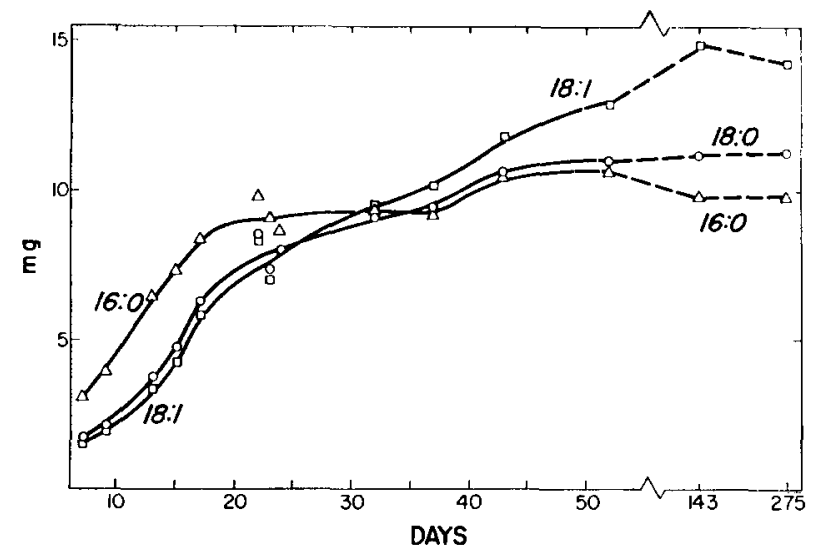

Fig. 5. Glycerophosphatide stearate, oleate, and palmitate content of whole rat brain as a function of age. 
it is being deposited at a rate which does not show a serious decrease over a 9-month period.

I think most observers of lipid developmental changes have missed the remarkable extent of this accumulation process: after weaning, there is only a minor increase in most fatty acyl lipids but the cerebroside-sulfatide mixture increases by $400 \%$. Cholesterol also shows a very prolonged accumulation and, after the first 15 days, its rate of accumulation is such that about 2.2 moles of cholesterol accumulate for every mole of galactolipid. This is close to the ratio observed in myelin, suggesting that these lipids are going primarily into myelin formation for the next 9 months or so.

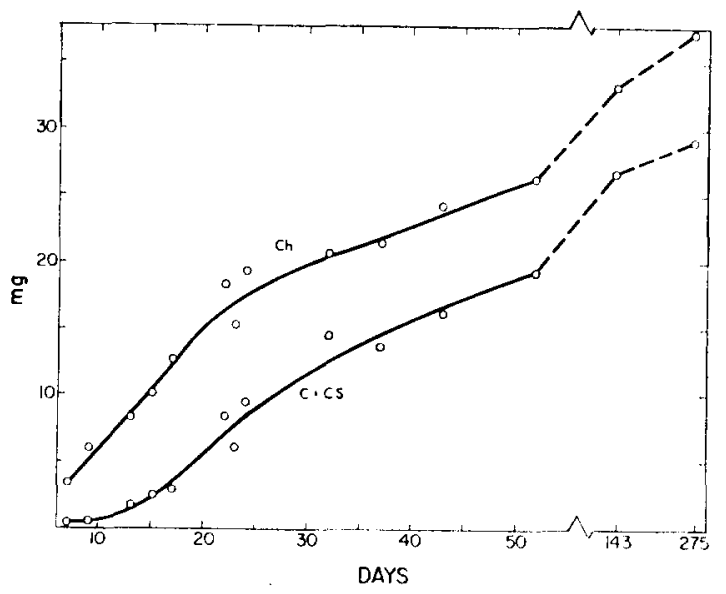

Fig. 6. Age changes in cholesterol (upper curve) and cerebroside + sulfatide of whole rat brain.

Given these observations, it seemed worth asking the questions: (1) is cerebrosidase present even before its presumed substrate is present? (2) is there any correlation between concentration of substrate and concentration of enzyme? The next figure (fig. 7) shows that the answers are, yes, partly. Measurable cerebrosidase activity is seen in 4-day old rats, but there is a considerable increase after 7 days, paralleling the rise in cerebroside content up to about 3 months of age. After this there is some decrease in hydrolase activity, despite the continuation of substrate deposition. It is of interest to see that considerable activity is present in 10-month-old rats, suggesting that there may be turnover of cerebrosides even in such mature animals. We have observed sulfatide formation in a rat over one year old ${ }^{1}$ ).

These findings lend additional support to the idea that lysosomes function in the normal degradative processes of turnover. 
Distinctly different maturational patterns are shown by arylsulfatase (assayed with nitrocatechol sulfate) and by $\beta$-glucosidase (assayed with nitrophenyl glucoside). Further differences were shown (fig. 8) for galactosidase (with nitrophenyl galactoside) and ceramidase. Both of these enzymes showed smaller increases than cerebrosidase and the peak activity was reached much earlier. It is tempting to suggest that both enzymes are primarily occupied with the degradation of gangliosides, the concentration of which

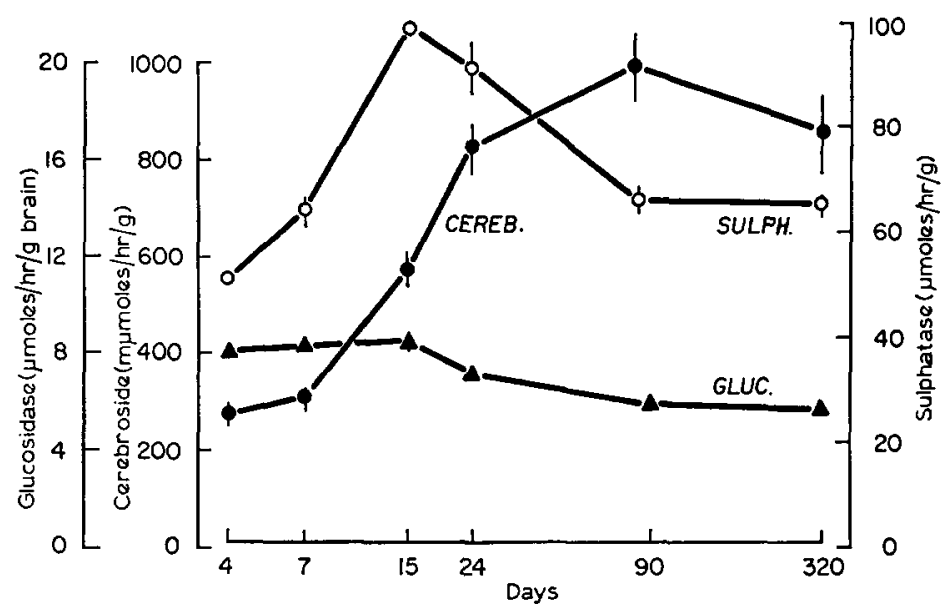

Fig. 7. Developmental profile of cerebrosidase, sulfatase, and nitrophenyl glucoside glucosidase. Age is shown logarithmically.

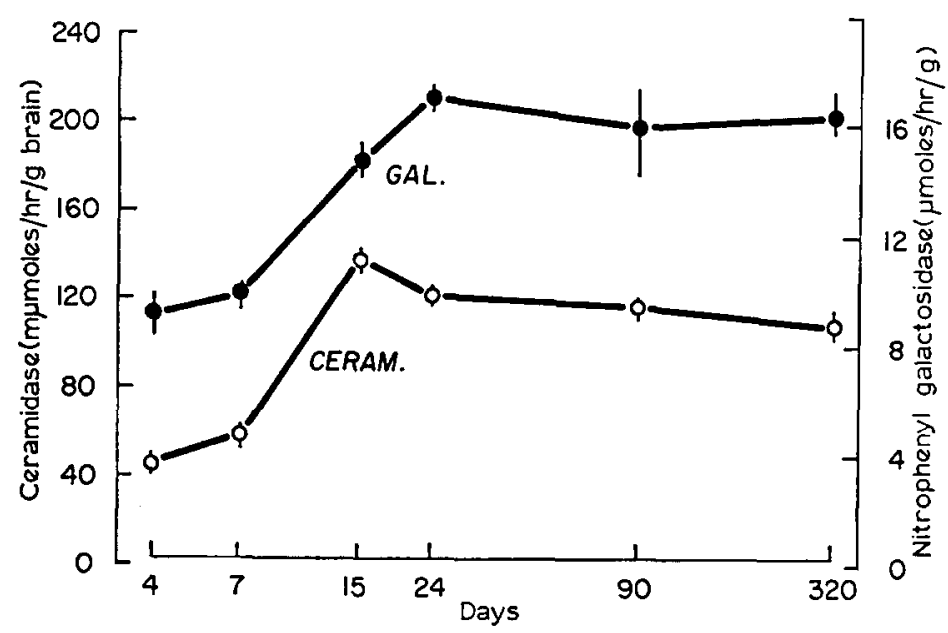

Fig. 8. Developmental profile of nitrophenyl galactoside galactosidase and ceramidase, with age shown logarithmically. 
levels off at about 3 weeks also. Both enzymes are also somewhat more active than cerebrosidase, in agreement with our initial finding that gangliosides turn over more rapidly than cerebrosides. Thus we have additional evidence for the normal functioning of lysosomal enzymes, a category under which these hydrolases seem to belong.

A further test of this hypothesis was made by Liselotte Hof in this laboratory ${ }^{16}$ ). She made lactosyl ceramide labeled with tritium by the same enzymatic oxidation route that we used for cerebroside. Galactose oxidase attacks lactose and the lactosyl lipid relatively poorly, but a reasonable yield of aldehyde was obtained by generous application of the oxidase. We used the incubation conditions described by Gatt and Rapport ${ }^{17}$ ) for demonstrating lactosyl ceramide galactosidase, and found partial parallelism between this enzyme activity and activity toward the synthetic substrate (fig. 9). Both peak at about 24 days and drop only slightly afterward. Thus assays made with the phenolic substrate probably reflect largely the activity of lactosyl ceramide galactosidase.

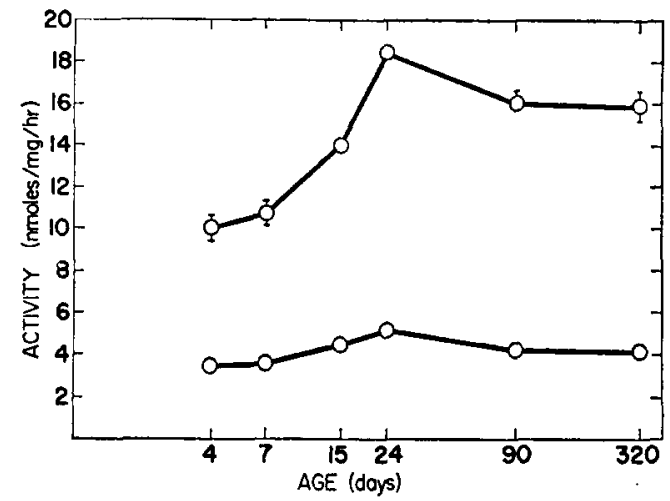

Fig. 9. Changes with age in nitrophenyl galactoside galactosidase (upper curve) and lactosyl ceramide galactosidase (lower curve) of rat brain.

Suzuki and Chen ${ }^{18}$ ) have reported that patients with the genetic defect,

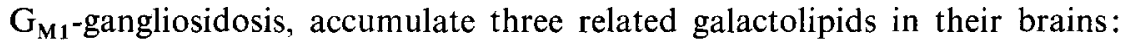
ganglioside $\mathrm{G}_{\mathrm{M} 1}$, asialo- $\mathrm{G}_{\mathrm{M} 1}$, and lactosyl ceramide. (These lipids appear to lie in the pathway of ganglioside degradation.) Okada and O'Brien ${ }^{19}$ ) showed that the tissues of such patients exhibit a great decrease in hydrolase

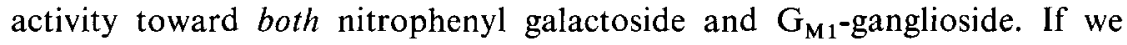
assume the disease involves a single enzymatic defect, then a single galactosidase may attack all three intermediates in ganglioside catabolism. Presumably this galactosidase is not the same one which hydrolyzes the trihexosyl ceramide found to accumulate in Fabry's disease. 
The existence of lysosomes was first intimated by the activating effect of detergents on certain particulate hydrolases. De Duve, Tappel, and others have shown that the enzymes in these particles can be made to exhibit higher activities by treatments which disrupt the physical integrity of the lysosomes. One may accordingly postulate that these hydrolases act in normal cellular metabolism without waiting to be disrupted but that disruption can lead to abnormally rapid and degenerative changes. It is thus possible that demyelinative processes can result from an increase in disruptibility or dispersibility of the lysosomes which act on myelin normally. We examined two neurological mutants found in mice, quaking and jimpy, with this possibility in mind. Both mutants show severe deficiency in content of myelin, cerebroside, and sulfatide 20,21 ).

The dispersibility of the lysosomal enzymes was determined by David Bowen by sonicating brain homogenates, then centrifuging the suspension at $100000 \times g$ for $1 \mathrm{hr}$. The activity in the supernatant was taken to be "dispersible" enzyme; that in the pellet, the "nondispersible" enzyme ${ }^{22}$ ). Let us first compare the total homogenate activities (table 4). The siblings of the

TABLE 4

Activities of lysosomal enzymes in mutant mice

\begin{tabular}{lccccc}
\hline \multicolumn{1}{c}{ Genotype } & $\begin{array}{c}\text { Brain } \\
\text { wt }\end{array}$ & Cerebrosidase & Arylsulfatase & $\begin{array}{c}\text { Aryl- } \\
\text { galactosidase }\end{array}$ & $\begin{array}{c}\text { Aryl- } \\
\text { glucosidase }\end{array}$ \\
& $(\mathrm{mg})$ & $($ nmoles $/ \mathrm{hr} / \mathrm{g})$ & $(\mu$ moles $/ \mathrm{hr} / \mathrm{g})$ & $(\mu \mathrm{moles} / \mathrm{hr} / \mathrm{g})$ & $(\mu \mathrm{moles} / \mathrm{hr} / \mathrm{g})$ \\
Quaking & 364 & 308 & 62 & 21 & 8.9 \\
Quaking siblings & 383 & 372 & 64 & 33 & 8.9 \\
Jimpy & 337 & 335 & 64 & 23 & 8.4 \\
Jimpy siblings & 362 & 343 & 63 & 23 & 8.1 \\
\hline
\end{tabular}

quaking mice exhibited slightly larger brains but distinctly higher specific activities with respect to cerebrosidase ( $21 \%$ higher). The other three enzymes were unaffected by the disorder ("aryl galactosidase" and "aryl glucosidase" refer to the enzymes which attack nitrophenyl glycosides). The jimpy mice showed a larger difference in brain weight but no significant difference with respect to all four enzymes.

The next figure (table 5) shows the results of the sonication experiment. The only significant difference is seen in the cerebrosidase of jimpy mice, where the ratio of dispersible: nondispersible activities was $47 \%$ higher in the mutants. The quaking mice show a small but non-significant increase in cerebrosidase dispersibility. Aryl galactosidase is rather similar in all four groups and somewhat more dispersible, like lactosyl ceramide galactosidase. 
Table 5

States of lysosomal enzymes in mutant mice

\begin{tabular}{lccc}
\hline \multicolumn{1}{c}{ Genotype } & \multicolumn{2}{c}{ Ratio of activities (dispersible/nondispersible) } \\
& Cerebrosidase & $\begin{array}{c}\text { Aryl- } \\
\text { galactosidase }\end{array}$ & Arylsulfatase \\
\hline Quaking & 0.19 & 1.3 & 2.9 \\
Quaking siblings & 0.15 & 1.1 & 2.9 \\
Jimpy & 0.23 & 1.3 & 3.9 \\
Jimpy siblings & $\mathbf{0 . 1 6}$ & 1.3 & 3.9 \\
\hline
\end{tabular}

Aryl sulfatase is unaffected by the disorders, but it is interesting that a strain difference between the two normal groups is visible. Aryl glucosidase is not shown because so little of it could be dispersed. Thus we see what may be a genetically controlled defect in the integrity of specific lysosomes bearing within them the galactosidase which hydrolyzes cerebrosides. Further work is scheduled to determine the nature of the defect, whether the enzyme is simply more readily released from particles, or whether the particles themselves have greater fragility. These findings are consistent with histological data from Sidman's laboratory, which show the presence in jimpy brains of sudanophilic lipid droplets and macrophages as myelination begins. Apparently these mice are able to form myelin components, but they hydrolyze the cerebroside as fast as it is formed. Quaking mice also show a lack of myelin, but none of these signs of demyelination, and the defect appears to be in synthesis rather than degradation. Pierre Morell in my laboratory has shown by in vitro assays that sphingolipid synthesis in quaking brains is seriously impaired.

Some additional studies of enzyme dispersibility were made by Dr. Bowen (table 6). In this experiment we measured three lysosomal enzymes in three fractions. " $C$ " refers to the cytosol, or highspeed supernatant obtained by centrifuging brain homogenates. " $D$ " is the dispersible fraction obtained by

TABLE 6

States of 3 lysosomal enzymes

\begin{tabular}{|c|c|c|c|c|c|c|c|c|c|}
\hline \multirow[t]{2}{*}{$\begin{array}{c}\text { Rat } \\
\text { age (days) }\end{array}$} & \multicolumn{3}{|c|}{$\begin{array}{l}\text { Cerebrosidase } \\
\% \text { in each state }\end{array}$} & \multicolumn{3}{|c|}{$\begin{array}{l}\text { Arylsulfatase } \\
\% \text { in each state }\end{array}$} & \multicolumn{3}{|c|}{$\begin{array}{l}\text { Arylgalactosidase } \\
\% \text { in each state }\end{array}$} \\
\hline & C & D & $\mathrm{ND}$ & C & D & ND & C & D & ND \\
\hline 5 & 2 & 17 & 81 & 1 & 79 & 20 & 4 & 55 & 42 \\
\hline 15 & 2 & 13 & 85 & 1 & 75 & 24 & 2 & 49 & 50 \\
\hline 320 & 5 & 7 & 89 & 3 & 72 & 24 & 12 & 39 & 50 \\
\hline
\end{tabular}


sonicating the cell particles and centrifuging as before. "ND" is the nondispersible fraction, still particle bound. Comparing the cytosol fraction, we see that very little of the enzyme occurs in this fraction but the proportion does seem to increase in later life. The proportion that is dispersible seems to decrease with age. Perhaps this means that older rats have tougher, stronger lysosomes but the enzyme which does get into the cytosol is destroyed less rapidly. These effects are seen with all three enzymes studied.

I have some recent data on the other side of the galactoside bond, so to speak. Over 10 years ago I found that the incorporation of labeled galactose into lipid by brain microsomes was considerably enhanced by the addition of ceramides ${ }^{23}$ ). This direction of research was dropped, partly because of the seemingly contradictory reports by Cleland and Kennedy ${ }^{24}$ ) and Brady ${ }^{25}$ ), whose work indicated a different route for cerebroside biosynthesis. Pierre Morell recently revived this problem in my laboratory and quickly discovered that only hydroxy cerebroside, the cerebroside containing hydroxy fatty acids, was formed in this system ${ }^{26}$ ). The ceramide that we had used had been made by the method of Carter, Rothfus, and Gigg ${ }^{8}$ ) rather than by direct synthesis, so it was a mixture of hydroxy ceramide and nonhydroxy ceramide. Experiments with the separated ceramides confirmed the observation and it seems highly unlikely that some physical difference in properties makes one ceramide a galactose acceptor and the other inert. We used ceramides deposited as a very thin film on Celite but independent, simultaneous work by Basu, Schultz, and Basu ${ }^{27}$ ) disclosed that emulsified ceramides act similarly.

We showed that the galactose donor was very likely UDP-galactose, which is synthesized by microsomes from UDP-glucose and galactose-1-phosphate. Table 7 shows the comparison of different sugar donors. The effect of adding

TABLE 7

Comparison of sugar donors for cerebroside biosynthesis by mouse brain microsomes*

\begin{tabular}{|c|c|c|}
\hline \multirow[t]{2}{*}{ Sugar donor } & \multicolumn{2}{|c|}{$\begin{array}{l}{\left[{ }^{14} \mathrm{C}\right] \text { sugar incorporated }} \\
\text { ( } \mathrm{m} \mu \text { mole })\end{array}$} \\
\hline & Acceptor & Control \\
\hline $\begin{array}{l}{\left[{ }^{14} \mathrm{C}\right] \text { galactose-1-P (40 m } \mu \text { moles) }+} \\
\quad \text { UDPGlc (70 } \mathrm{m} \mu \text { moles) }\end{array}$ & 1.54 & 0.23 \\
\hline $\begin{array}{l}\left.\left[{ }^{14} \mathrm{C}\right] \text { glucose-1-P (10 m } \mu \text { moles }\right)+ \\
\text { UDPGal (70 } \mathrm{m} \mu \text { moles })\end{array}$ & 0.05 & 0.02 \\
\hline [Galactose- $\left.{ }^{14} \mathrm{C}\right]$ UDPGal ( $8.5 \mathrm{~m} \mu$ moles $)$ & 0.77 & 0.10 \\
\hline [Galactose-14 C] UDPGal (17 m $\mu$ moles) & 1.02 & 0.12 \\
\hline
\end{tabular}

* Incubations were carried out as described in the text except that the only sugar and/or nucleotide-sugar additions were as indicated above. The acceptor was $0.5 \mathrm{mg}$ of hfa-ceramide coated on Celite. Control incubations contained uncoated Celite. 
hydroxy ceramide (left column) is to increase cerebroside synthesis by 7 -fold or more, but the radioautographs obtained with TLC plates made from the products (fig. 10) show that the effect of lipid acceptor is even more marked. The cerebroside formed in the absence of hydroxy ceramide is evidently long and short chain nonhydroxy cerebroside (bands A and B). In the presence of hydroxy ceramide, there is still some short chain nonhydroxy cerebroside

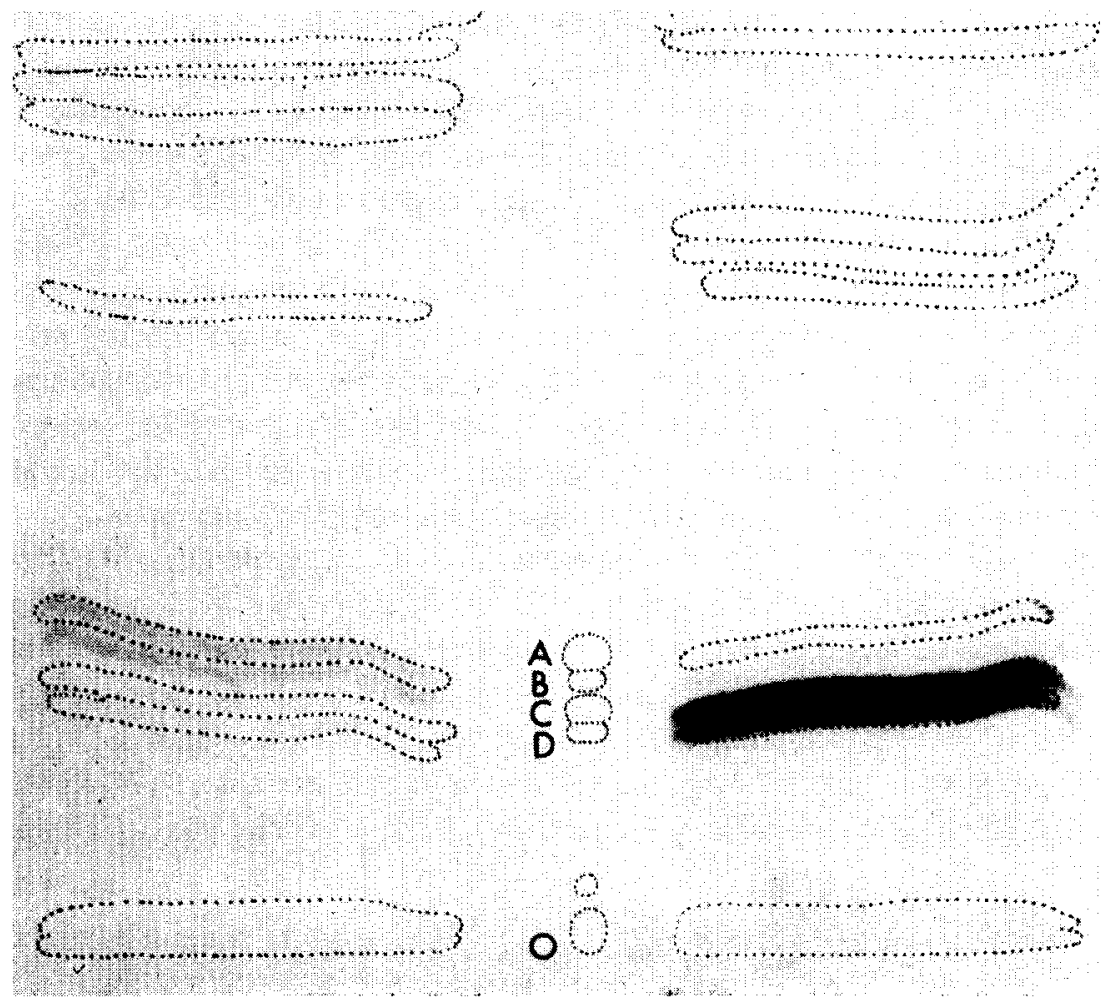

Fig. 10. Radioautograph of cerebroside-containing fractions separated by TLC (developed twice with C-M-W 144-25-2.8). The dotted lines indicate areas visualized with iodine. Left side: after incubation with nonhydroxy ceramide; right side, after incubation with hydroxy ceramide.

being made (band B) but the synthesis of long chain cerebroside is completely repressed and by far the major product is a mixture of long and short chain hydroxy cerebroside. (Our hydroxy ceramide was made from beef spinal cord, which is rich in h18:0 as well as the more usual long-chain hydroxy acids.) Since mouse brain, our source of microsomes, has very little h18:0, it is evident that the galactosylating enzyme is not specific for chain length.

The product was shown to be galactosyl ceramide rather than glucosyl 
ceramide by use of borate-impregnated TLC plates ${ }^{28}$ ). To eliminate the possibility that the galactose had added to the hydroxyl group of sphingosine or the fatty acid, we hydrolyzed the radioactive product with the TaketomiYamakawa procedure ${ }^{29}$ ) and isolated the resultant psychosine, which migrated in the normal way on TLC. Our method of isolating the psychosine from the hydrolysis mixture looks like a useful one, which we are currently modifying for preparative scale work. The hydrolysis mixture is acidified with citric acid and extracted with chloroform-methanol, which pulls out the fatty acids and leaves the psychosine in the aqueous citrate layer. The latter is then made alkaline, $\mathrm{KCl}$ is added to raise the ionic strength, and the psychosine is extracted out with chloroform. The yield of radioactive psychosine under the conditions used was the same as found with tritium-labeled cerebroside, about $70 \%$.

We are now faced with an unexpectedly sharp matter of specificity in cerebroside biosynthesis. Evidently nonhydroxy cerebroside is made by an entirely different route, for some inexplicable reason. Its synthesis evidently uses UDP-galactose, for we observed competition for this donor when hydroxy ceramide was added. Psychosine seems like a good candidate as intermediate, for we could readily confirm the Cleland-Kennedy reaction between sphingosine and UDP-galactose. Nevertheless, psychosine (made from tritium-labeled cerebroside) proved to be inert and attempts at demonstrating its formation as an intermediate by pulse-chase incubations proved futile. We can obtain reasonable amounts of nonhydroxy cerebroside by simultaneous incubation with long chain base, UDP-galactose, and fatty acyl coenzyme A. If the acyl-CoA is omitted, we obtain psychosine; if the sugar transferring system is omitted, we obtain ceramide, as reported by Sribney ${ }^{30}$ ). We are still attempting to dissociate the synthetic system.

\section{References}

1) N. S. Radin, F. B. Martin and J. R. Brown, J. Biol. Chem. 224 (1957) 499

2) A. S. Balasubramanian and B. K. Bachhawat, Biochim. Biophys. Acta 106 (1965) 218

3) G. M. McKhann, R. Levy and W. Ho, Biochem. Biophys. Res. Commun. 20 (1965) 109

4) Y. Fujino, J. Biochem. 40 (1953) 251

5) S. J. Thannhauser and M. Reichel, J. Biol. Chem. 113 (1936) 311

6) H. E. Carter and Y. Fujino, J. Biol. Chem. 221 (1956) 879

7) D. Shapiro and H. M. Flowers, J. Am. Chem. Soc. 83 (1961) 3327

8) H. E. Carter, J. A. Rothfus and R. Gigg, J. Lipid Res. 2 (1961) 228

9) A. K. Hajra, D. M. Bowen, Y. Kishimoto and N. S. Radin, J. Lipid Res. 7 (1966) 379

10) B. W. Agranoff, N. S. Radin and W. Suomi, Biochim. Biophys. Acta 57 (1962) 194

11) D. M. Bowen and N. S. Radin, Biochim. Biophys. Acta 152 (1968) 587

12) S. Gatt, J. Biol. Chem. 241 (1966) 3724

13) D. M. Bowen and N. S. Radin, Biochim. Biophys. Acta 152 (1968) 599

14) D. M. Bowen and N. S Radin, J. Neurochem. 16 (1969) 501

15) Y. Kishimoto, W. E. Davies and N. S. Radin, J. Lipid Res. 6 (1965) 532 
16) N. S. Radin, L. Hof, R. M. Bradley and R. O. Brady, Brain Res. 14 (1969) 497

17) S. Gatt and M. M. Rapport, Biochem. J. 101 (1966) 680

18) K. Suzuki and G. C. Chen, J. Lipid Res. 8 (1967) 105

19) S. Okada and J. S. O'Brien, Science 160 (1968) 1002

20) R. L. Sidman, M. M. Dickie and S. H. Appel, Science 144 (1964) 309

21) N. A. Baumann, C. M. Jacque, S. A. Pollet and M. L. Harpin, European J. Biochem. 4 (1968) 340

22) D. M. Bowen and N. S. Radin, J. Neurochem. 16 (1969) 457

23) N. S. Radin, in: The biology of myelin, S. R. Korey, ed., Harper, New York, 1959, p. 271

24) W. W. Cleland and E. P. Kennedy, J. Biol. Chem. 235 (1960) 45

25) R. O. Brady, J. Biol. Chem. 237 (1962) PC2416

26) P. Morell and N. S. Radin, Biochemistry 8 (1969) 506

27) S. Basu, A. Schultz and M. Basu, Federation Proc. 28 (1969) 540

28) E. L. Kean, J. Lipid Res. 7 (1966) 449

29) T. Taketomi and T. Yamakawa, J. Biochem. 54 (1963) 444

30) M. Sribney, Biochim. Biophys. Acta 125 (1966) 542

31) K. C. Kopaczyk and N. S. Radin, J. Lipid Res. 6 (1965) 140 